\title{
Current a Key Element Affect the Productivity in Construction Project in Thailand from Different Viewpoints
}

\author{
Thanawatdech Thirapatsakun
}

Thayawat Engineering and Construction Co., Ltd. Thailand

Copyright $(2016$ by authors, all rights reserved. Authors agree that this article remains permanently open access under the terms of the Creative Commons Attribution License 4.0 International License

\begin{abstract}
The current issue, contractors had been confirmed what mostly low productivity was: Thai construction industries had been suffered from a chronic disease as the lack of competitive advantage and improve slim profit margins. Symptoms have long been recognized in several construction projects. In any given geographical area, contractor's finance difficulties, incomplete design, labor shortage, poor skill worker, material shortage, equipment and tool shortage, and poor project management as well as construction mistake and defective work trail to reworks are essentially the same characteristic. One of the few opportunities to improve the identifying current a key element effect is to increase productivity. The papers had been doing to identify different points to increase productivity at the construction projects in Thailand. The owner, consultant, contractor, subcontractor, and suppliers were discussions and data collected. In addition, that was concluded to the key element make practice specifically and management tool would be increase productivity. Perhaps most important, the project management could considered continuous improvement under a key element affecting the productivity by the owner implement aspect, employees implement and social, occupational safety and health implement aspect. Meanwhile, the supervisor and crew with close the communication with all crews and review work method or work instruction as well as the training that had been able to yield the greatest productivity improvement.
\end{abstract}

Keywords Productivity, Construction Project, Thailand

\section{Introduction}

This study is part of broader research project that seek to analyze the actual and potential key element affect the productivity of Thai's construction industry form the different viewpoints. Thailand have outlook through the lens of construction industry right and interests. Several years after the Asian finance crisis until political crisis date, Thailand's economy in the early 2015 began to see a sign of modest recovery. The Thailand's government has planned approach to stimulate economic activities through public investment infrastructure. Also currently, the outlook for Thai construction industry is quite optimistic. The development of the mass transit in Bangkok (sky train and subway), high speed railway and medium speed railway for cargo transport, As a result provide the developers and opportunity to construction more residential high rise condominiums along the mass transit routes urban and extent to vicinity. In addition, the cabinet of Thai government approved three-tax package aiming at reviving the flagging property sector, stimulating start-up and rebuilding investors confidence on Oct 13, 2015, to moves will push-up housing transferred. Increased transfer activity should build developers financial strength, enabling new investment and helping Thai economic growth. This is one strategies driving of government reform.

\section{Literature Review}

Thai construction industry market will continue to grow mainly over the coming decade. Meanwhile, increasing productivity is most of the key component of every organization's success and competitiveness in the industries. Productivity formulate directly into owner side, employee side and social side lead to cost effective and profitability [11](Proverbs, Holt, \& Olomolaiye, 1998). Beside, the project environment in many organization of Thai construction industry in current special challenger for project manager that almost presuppose extensive of preparation poor productivity even before a project commences. These are challenge arise mainly from fluctuate situation and basis risks such as financial crisis, political instability, excessively bureaucratic contact procedure, and shortage of employees such as labor supply, migrant workers, poor workmanship, incompetent supervisors, and lack of adequate social 
well-being and safety works culture such as deprived of labor right, abusive practices by employers, unsafe behavior and unsafe work condition. In recognition of these unique problems, several previous research studies have suggested that these are a need to use management tools and make practical suitable to increasing productivity of construction project management. Furthermore, the purpose of this paper is therefore to discuss the key element of owner, employees, and social, occupational health and safety implement aspect of construction project management and it is different viewpoint significance for improving productivity in Thailand contractors industry.

\section{Owner Aspect}

The importance of owner's productivity issue has been recognized as the initial until completing construction project. The activities that contribution the implementation of delivering a project process can be step in from initial to completion. First phases is concept formulate had significantly of influence on subsequent project expenditure and implementation strategies of construction project formulation, feasibility studies, the tendering period, and construction masters planning works process are owner activity which. In respect of decisions and commitment made during the early construction project phases have a decision to emerge is made at the end of this phases. Meanwhile, a commitment has been to proceed with development phases of the construction project is required to determine the project scope of works such as the design the construction project for information project product and detail design for the contractual and technical specification strategies such as cost and budgetary control, financial and cash flow schedule details, project scheduling and tasks sequencing details, specification of contract term and condition, term of reference: TOR, tendering and bidding documentation. Also Makulsawatudom and Emsley (2002)[5] described that owner provide limited time and budget for designer to complete the design in order to expedite the bidding process lead to drawing incomplete, insufficient detail, impractical and contain conflicts. Meanwhile, the owner were rapidly changing mindset from marketing situation affecting is often reason of drawing incomplete. In addition, construction project planning is the purpose of determining process tasks and appropriate objective for the achievement of predetermined project target. The significance of the planning process in practices as progress follow up and monitoring control process to improving project productivity [14,3](Syal, Grobles, Willenbroch. \& Parfill, 1992; Faniran, Oluwoye, \& Lenard, 1994). According to Faniran, Oluwoye, and Lenard (1994)[3] demonstrated that in order to implementation improve planning effectiveness, the construction project planning need to determination of appropriate execution strategies base on a systematic evaluation of alternatives. However, Oqunlana, Promkuntong, and Jearkjirm (1996)[8], described that it would contribution the construction process if the owner to the construction project spend more time and concentrated on development planning phases. In addition, the upstream investments of owner issue adequate resource in the organizational and management of initial until completion construction project to provides a solid foundation for downstream. Project success, the finance inadequate access to short or long term funding to finance contribution project has often cited as a major problem faced. The contracting organizations often lead to the stoppage of work at construction project site until sufficient finance is available to resume construction project activities again. This case had high confidence degrees of maintain work progress all necessary owners should establish funding prior to proceeding involvement and financial expert should be sought on the concept phases. That will be used major contracts are left at the end of development in project implementation. Meanwhile, Third phases of construction project process is execution phases that the organization executing the construction project contract and monitoring to activity project management such as productivity of workers, equipment and construction method, and wise material procurement practice and supply chain management, social and wellbeing, safety work and environment. The product of construction project is substantial completion at the end of execution phases. Last phases of construction project is completion phases have project handover of construction product, project closed, are therefore the opportunity way to closure all of risk from overall project costs. Smith, Jackson, and Wyatt (1998) [13] supported the identification of the strategic need of project owner is a significant concern in construction project process as development phases when them need objectives and requirement are classified into the definition of project scope of work such as work categories; new building work, extensions work, renovation work, refurbishments work, recycling work or combination work of these.

\section{Employee Aspect}

Employees are playing very important role in Thailand construction industry. Unlike other industries whose increasing productivity was enhanced by paradigm shift and new emerging technologies. Meanwhile, Thailand construction industry is still a labor-intensive and low-tech sector as poor productivity portion human capital is most important to deploy within construction project [4](Loosemore, Dainty, \& Lingard 2003). Employee increasing productivity, Nesan and Holt (1999) [7] described a "New Construction Philosophy", the idea of increasing degree of employee empowerment. In addition, Olomolaiye, Anande, and Frank (1998) [9] productivity " Lean Construction Philosophy" which combines existing techniques and principles in a new dimension for productivity improvement and cost reduction by stimulate employees. In the Thailand, there is a growing shortage of skilled construction workers because construction jobs does most provide the appeal reason in once did as competitive wages, to hard works, dirty works, acceleration work, and inferior the acceptance in society. Current, the majority of 
worker entering into the construction workforce are from agriculturists, foreigner and immigrant workers and chronically unemployed person. Meanwhile, Thailand construction industry relies heavily on Myanmar and Cambodia workers.

Social, occupational safety and health aspect

Social aspect: The fact visual and trends of the Thailand construction industry. According to the international labor organization (ILO), there are more than 395,000 of migrant workers at construction industry [10](Philip, 2007). Meanwhile, Thailand construction industry thrives in places with greatest need for infrastructure development, both the private and public sectors. It is also interesting of the unique feature is the fact that products are often produced or assembled at the construction site requiring the workforce to be highly mobility and interchanging of worker group as depend on tasks sequence process. In addition, migrant workers status, Thailand was the main imported countries while Myanmar, Vietnam, Philippine, and Lao PDR was the worker exports country. The construction site is moment increasingly becoming to keep labor as informal. Because of economic globalization and mobility works through open Asian Economic Community (AEC.) as possible so as to cut off production costs lead to employers obscuring employee-employer relationships through subcontracting and hiring migrant workers from the sending countries when unemployment and underemployment level are high. Meanwhile, Thailand construction industry has traditionally been using subcontractor rather than direct employment for most of it is labor supply [2](Chang, D. 2008). Process of hiring, recruiting workers has become the job of subcontractor groups rather than major construction companies or main contractor firm. The subcontracting chain usually consists of major contractor groups and just one layer of subcontractor who serve as some sort of middlemen and who are leadership of groups and skilled worker themselves. The hiring of general migrant workers is often done through informal connections between workers and the middlemen. In addition, the hiring migrant worker management has been decentralized to multiple layers of each group within subcontracting chains. Indeed, construction migrant workers are probably the worst victims of subcontracting. Meanwhile, situation of irregular and informal workers essentially means lacking empowerment from unorganized workers lead to unprotected labor such as low wages, unhealthy working condition, long work hours, and the absence of entitlements such as paid day-off and vacation, sick leave, health insurance, social security benefits and pension funds. Therefore, indirect hiring of migrant construction worker is the norm rather than the exception in this part of the real world [2](Chang, D. 2008).

Occupational safety and heath aspect:

Construction works is known to be dirty, hard work, difficult and dangerous, unique compared to other industries. Characteristic of construction process are constrained under time and budgetary, pressures, temporary workers with various skills, impact of external environments and works influenced by weather conditions. Thus, the unique characteristic lead to construction project faced hazardous conditions that are potential to cause accidents. Thai regulation, occupational safety and health in the construction industry are definitely a grave concern for worker and unions. Construction workers, especially those hire through subcontracting and other irregular hiring practices are insufficient provided with the appropriate safety tool, personal protection equipment (PPE). Meanwhile, employees and subcontractors have mindset with standpoint safety practices as unnecessary costs rather than as necessary investment or part of their accountability in maintain to safety works standard. Safety strategy has been important for increasing productivity in construction industry. Safety culture is one of this. Turner (1992)[17] as established definition is the set of people's shared beliefs, norms, attitude and expectations shared collectively by members of a society, organization or group. This is essentially key element affecting the productivity.

\section{Analysis}

This study is primarily sourced from secondary data. It relies heavily on previous studies such as (i) "Factors Affecting the Productivity of the Construction Industry in Thailand: the Project Manager's Perception" research and written by Arun Mukulsawatudom and Margaret Emslsy in 2001, (ii) “ Current Practices of Human Resource Management (HMR) in Thailand Construction Industry: A Risk and Opportunity Perspective" conducted and written by Nakhon Kokkaew and Somjintana Koompai in 2012, (iii) "Global Construction and Asian Workers: Expansion of TNCs in Asia and Implications for Labour" research and written by Deaoup Chang in 2008, (iv) " Construction Workers Perception Toward Safety Culture" research and written by Andi 2008. The data gather and collected were discussions from owner, consultant, contractor, subcontractor, and suppliers whom had working in housing construction project.

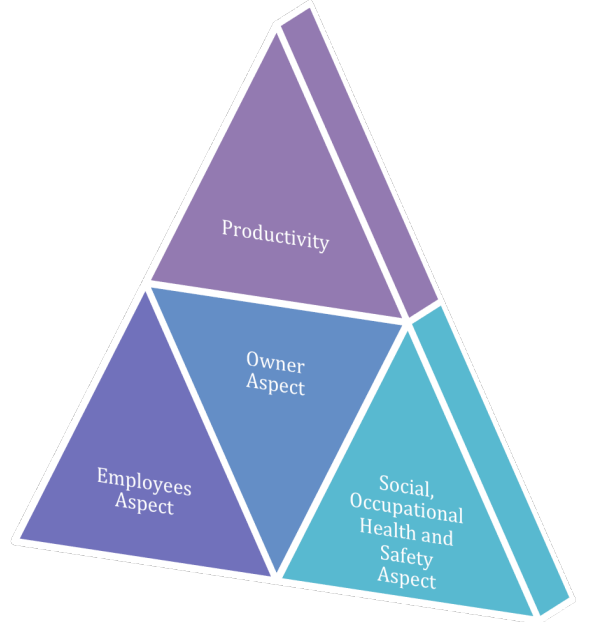

Figure 1. Key element affecting the productivity 
Essentially key element affecting the productivity based on the literature review. Poor productivity issue; although previously studies has been carried out on lack of materials, incomplete drawings, incompetent of supervisors, lack of tool and equipment, absenteeism, poor communication, instruction time, poor site layout, inspection delay, and rework were found to be most significant event affecting construction productivity in Thailand also event that poor management is main reason for decreased construction productivity in Thailand [5](Makulsawatudom \& Emsley, 2002). Meanwhile, efforts to survive and increasing productivity in construction requires and understanding of the various key element affecting to productivity management as a path to understanding the identifying way to increasing productivity of the construction project. Beside that, efforts to improve productivity in construction industry can essentially be done by owner, employees, and also social views in order to understanding critical factors affecting productivity can be used to selected a strategy to contribution to improve the productivity of construction project performance. In addition, stakeholder in each organization to formulate based on knowledge and understanding of essential key element affecting to construction productivity used strategies selects. Therefore, strategy selected is needed to determine the focus of the necessary step in owner, employees, and also social views. Thereby increasing productivity and overall performance.

Essential key element affecting the productivity by owner aspect: initially organization established to non-construction work solution may be a better solution this involves present and future activities into organizational arrangement. These decision making by owner include preparation work such as proposal for outsourcing, subcontracting, devolution and delegation, privatizations, quality management, safety and environment regulation, bureaucratic contract procedure and other productivity management method (capital implementation, equipment and tool available to operate, materials on time delivery and availability of substitutes, human resource activity) that resolve and dissolve the problem being analyzed to selected new optional for alternative works. Hence, the construction project strategies wanted had been pursuit then it should result in a rigorously, simple to construction implementation, clearer view of project goals, that recommends the best mean to achieve the identified goals and have overcome or increasing productivity. Almost activity above said was formulate and decision by owner.

Essential key element affecting the productivity by employee implement aspect: The main problems faced by the Thailand construction industry are the lack of appropriate technical skill, familiarity with work method and material characteristic, language barriers, and education background. In addition, Unskillful foreign laborers are widely used because the wage rates of foreign laborers are much cheaper than local laborers. To handle this entire problem, organizations are adopting human resource management as a tool to implementations achievement increasing construction productivity. The role of leadership of construction manager has been essentials key to success of construction project productivity [16] (Toor, and Ogunlana, 2010). Moreover, Tabassi and Baker (2009)[15] suggested to improve the productivity of employment both short-term and long term period training at the place like training center, increase efficiency than on the job training (OJT). Another study motivation practices that achievement contribution to satisfaction for the engineer employees who prefer monetary rewards to achievement but they did not indicate the relationships between job satisfaction and performance to increasing productivity [12](Rthankoon, \& Ogunlana, 2003). Furthermore, employment of construction industry found that the major problems with employee's productivity in Thailand are recruitment of engineer, supervisor, and local workers high rate turnover, absenteeism at the workplace. Hence, through essentially key element affecting the productivity and identifying way to increasing way are leadership, training and development skill program, wage compensation and benefits, level of mechanization and technology, monetary incentives, and evaluation tools is the set of forces. That causes people to behave in certain ways activity in order to improve productivity by quality management tools such as 7 QC Tool, the PDCA continuous improvement cycle, Kaizen continuous improvement, total quality management, total productive maintenance, balance score card, and just in time.

Essential key element affecting the productivity by social, occupational safety and health implement aspect: The employment pattern of migration of construction worker is an irreversible trend. Thailand was in the issue raised of migrant workers experience similarly of conclusions as migrant workers are paid lower wages for the same kind of work done by local workers. Also, does not willing to pay of lower wage, they are facing gain advantages often have to pay wrongful deduction of levies. They do not perceived comfortable about employment benefits other than their low wages. Furthermore, their living conditions are often as worse than their working conditions. All construction migrant workers are often deprived of labor rights and particularly the right to job unions. Meanwhile, their often have very few knowledge about their rights and entitlements, and thus are unable to protect themselves and jobs. Moreover, it is very difficult for migrant workers to set up organization themselves into unions. Most employees are insufficient treat well as abusive practices by employers. They often done in connivance with recruitment agents are very smart in escaping from or circumstance the law and the bureaucracy. Generally, employers possessed the passports of their migrant workers. Some employers even physically abuse their employees. Furthermore, almost of migrant workers do not have employment contracts documentation, work contracts are often verbal, neither written nor legally binding. Hence, the essence indicated to migrant worker need obligingness and supported to file claim for proper pay and other right and entitlement of employment.

Essential key element affecting the productivity by 
occupational safety and health implement aspect: The safety culture was composed of as main key element to safety program should be initialed and formulate a policy indicating a commitment to achieve a successful safety program in workplace from top management of an organization. Meanwhile, safety rule and procedure are difficult to understand and impractical to objective with local and migrant workers within the current condition and over specification. So the presentation applies of safety rules and procedures distinct to multimedia tool such as picture exhibition, video clip, for orientation and training about accident caused by unsafe conditions. Because it is give clear picture in mind and border of the safety program implementation in construction project. In addition, many human errors represent in cost and time overruns in construction project, design quality problems, construction defects and unsafe work condition, accident in workplace, damming missing communication by members of society, organization or groups of construction project at all. So communication is this important, in order to support safety work program, to mark available appropriate information line from management to workers coordination work responsibility activity to achieve and safety works. Learning Support, knowledge and worker competence was one of importance for safety program. The workers competencies can be enhanced through training and practices consistent attention in construction procedure or construction method completely. They are adequate knowledge, skill and ability to their works particularly is lead to minimize accident from risk and dangers in their works. Furthermore, environment and society workplace are showing the situation and living condition in organization with in place where the worker work. This covered issue of moral and motivation of worker has important to improvement productivity and safety behavior. Furthermore, low morale and motivation behavior of employees are cause from as work hard, boredom, tight schedule, blaming culture, and abusive practices by employers. Which has directly lead employee initiated unsafe behavior in their works and workplace. Hence, worker involvement and awareness is activity in building workers awareness toward implement safety program such as participation during planning and development safety program, and accident or unsafe act investigations and reporting. Thus, the activities of worker involvement will give more motivation influence to safety behavior of employees as individual or a team groups in workplace and their jobs.

\section{Conclusions}

Current, Thailand construction industry has in vital to development efforts at the international levels. Despite, the recent both external and internal country financial crisis, and political crisis, and political crisis, this industry will remain a major contribution to economic and solid development in Thailand. Meanwhile, owner, employees, social, occupational health and safety implement aspect plays an important role in order to improvement productivity through effective be owner aspect to the decision making and commitment to construction process execution, clearer view of project goals. If the owner to spend more time and concentrated on development planning phase and issue adequate resource to the organization and management from initial until completion construction project that is provide a solid foundation and that suggestion the best way to achieve the productivity by owner implement aspect. Thailand construction industry is depending on capital and labor intensive. It also involves huge infrastructure projects. That requires tremendous number of construction workers, professional and general employees. Therefore, the employees implement aspect can improve its productivity through the effective use of human resource management as role of leadership, job satisfaction, training and development skill program, wage compensation and benefits, level of mechanization and technology, monetary incentive, evaluation tool for improve productive. Even though, critical to the construction industry, most migration of construction worker is mostly that is unskilled labor. Migrant workers are unfortunate among the most vulnerable and exploited of worker as especially for migrant worker in the construction industry. The practices of subcontracting that dispose migrate worker prone to exploitation, low wage, poor and unsafe working conditions and job instability. Thailand has yet to introduce limitation on the multiple layering of subcontracting and impose penalties for violation by subcontractors. Also find a way to exact accountability from main construction contractors who usually deny responsibility for the active of their subcontractors. As it is, migrant workers, is clearly discriminated against in terms of economic benefits and other entitlement from employers. Moreover, occupational safety and heath implement aspect can improve its productivity though the effective use of the set of safety culture is compose of essential element as top management commitment, safety role and procedures, communication, work competency work environment and workers involvement. However, various identifying way to increasing productivity as essentially key element of owner implement aspect, employers implement aspect and social occupational health and safety implement aspect should now be focused on these. Therefore, using these papers as the foundation, future studies could be concentrated to reaches suitable for the boundary continuous improvement to sustainable in construction industry.

\section{REFERENCES}

[1] Andi. Construction Workers Perceptions Toward Safety Culture, Civil Engineering Dimension, Vol. 10 (1), pp. 1-6, (2008).

[2] Chang, D. Global construction and Asian workers: Expansion of TNCs in Asia and implications for labour. Building and 
Wood Workers' International (BWI) and Asia Monitoring Resource Center (AMRC), (2008).

[3] Faniran, O.O. Oluwoye, J.O. and Lenard, D. Effective construction planning. Construction Management and Economics, Vol. 12, pp 485-499, (1994).

[4] Loosemore, M., Dainty, A., Lingard, H. Human Resource Management in Construction Projects: Strategic and Operation Approaches. Spon Press, (2003).

[5] Makulsawatudom, A. Emsley, M. Critical factors influencing construction productivity in Thailand. In Proc of CIB $10^{\text {th }}$ International Symposium Construction Innovation and Global Competitiveness, Cincinnati, Ohio, USA, Sept 9-13, 2002, pp. 182, (2002).

[6] Nakhon, K. Somjintana K. Current Practices of Human Resource Management (HMR) in Thai Construction Industry: A Risk and Opportunity Perspective, Review of Integrative Business Economics Research, Vol. 1(1), pp. 1-14, (2012).

[7] Nesan, L.J. Holt, G.D. Empowerment in the Construction: The way Forward for performance Improvement. Herfordshire, England: Research Studies Ltd, (1999).

[8] Ogunlana, S.O, Promkuntong, K., Jearkiirm, V. Construction delays in a fast-growing economy: comparing Thailand with other economics. International Journal of Project Management, Vol. 14, No. 1, pp.37-45, (1996).

[9] Olomolaiye, P.O., Ananda, K. W., Frank, C.H. Construction Productivity Management. Essex, England: Addison Wesley Longman, (1998).

[10] Philip, M. The economic contribution of migrant works to Thailand: Toward policy development. Bangkok, International Labour office. Vol.32 pp.1-14. (2007).
[11] Proverbs, D.G, Holt, G.D, Olomolatye, P.O. 'A comparative evaluation of planning engineer's formwork productivity rate in European construction' Building and Environment, Vol. 33(4), pp. 180-188, (1998).

[12] Rthankoon, R., Ogulana, S. Testing Herzberg's two-factor theory in the Thai construction industry. Engineering, Construction and Architecture Management, Vol. 10 (5), pp. 333-341, (2003).

[13] Smith, J., Jackson, N. Wyatt, R. Strategic Needs Analysis: Searching for Viable Solutions. Plenary Paper, Proceedings of the COBRA Construction and Building Research Conference 1998, 2-3 September 1998, Oxford Brookes University, the Royal Institute of Chartered Surveyors, London, Vol. 1, pp.60-66, (1998).

[14] Syal, M.G., Grobler, F. Willenbrock, J.H. and Parfitt, M.K. Construction Project Planning Process Model for Small-Medium Builders. Journal of Construction Engineering and management. Vol. 118, No. 4, pp. 651-666. (1992).

[15] Tabassi, A. A., Baker, A.A.H. Training, Motivation and performance: the Case of Human Resource Management in Construction Project in Mashhad, Iran. International Journal of Project Management, Vol.27, pp.471-480, (2009).

[16] Toor, S.U.R., Ogunlana, S.O. Beyond the 'iron triangle': Stakeholder perception of key performance indicators (KPI) for large-scale public sector development projects. International Journal of Project Management, Vol. 28 (3), pp. 228-236, (2010).

[17] Turner, B.A. The sociology of safety in Engineering Safety, Blockkey, D.(Ed.), McGraw Hill, London, pp. 187-201, (1992). 